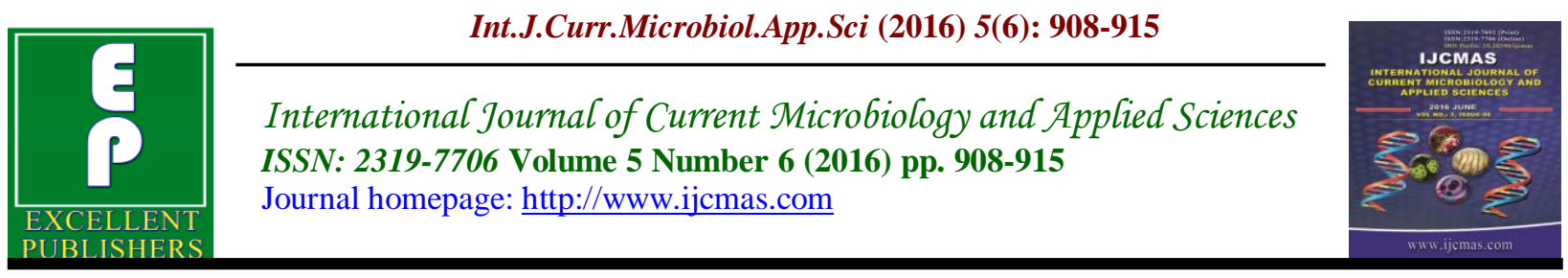

Original Research Article

http://dx.doi.org/10.20546/ijcmas.2016.506.098

\title{
Immunoglobulin E, Interleukin-17A and Transforming Growth Factor- $\beta 1$ Levels in Children with Nephrotic Syndrome
}

\author{
Ahmed Abdul-hassan Abbas ${ }^{1}$, Yasmin Sahib Mahdi ${ }^{2}$ and Shatha Hussain Ali ${ }^{3 *}$ \\ ${ }^{1}$ Department of Microbiology, College of Medicine, Al-Nahrain University, Iraq \\ ${ }^{2}$ Department of pediatrics, College of Medicine, Al-Nahrain University- Iraq \\ ${ }^{3}$ Department of Pediatrics, College of Medicine, Al-Nahrain University, \\ P. O. Box 70074, Baghdad-Iraq \\ *Corresponding author
}

\begin{abstract}
A B S T R A C T
Keywords

Nephrotic

syndrome,

$\mathrm{IgE}$,

IL-17A,

TGF- $\beta 1$,

Children.

\begin{tabular}{l}
\hline Article Info \\
\hline Accepted: \\
20 April 2016 \\
Available Online: \\
10 June 2016
\end{tabular}

The etiology of Nephrotic syndrome (NS) is unknown however various evidences suggest that immune dysfunction play a key role in the pathogenesis of NS. This study was established to investigate the role of $\operatorname{IgE}$ in the pathogenesis of NS, and some immune mediators (IL-17A and TGF- $\beta 1$ ). Fifty three patients with NS were enrolled in the present study, aged from 2 to 17 years. Control group consist of 27 healthy children. Blood samples were collected from patients and controls to assess serum levels of IgE, IL-17A and TGF- $\beta 1$ by Enzyme-Linked Immunosorbant Assay (ELISA). The level of both IgE and IL-17A was significantly higher in NS patients than healthy control, and the level was higher in patients with resistant to steroid than sensitive and in relapse phase than in remission phase and in patients with history of allergy than those patients without history of allergy. Whereas the level of TGF- $\beta 1$ was lower in NS patients as compared with control and lower in patients with relapse phase and newly diagnosed than in patients with remission phase and lower in steroid resistant patients than steroid sensitive patients .While the level of TGF- $\beta 1$ was higher in patients with history than those without history of allergy. Patients with NS exhibit increased serum level of $\operatorname{IgE}$ and this may be related to sensitivity to steroid treatment. Moreover, IL-17A/TGF- $\beta 1$ ratio imbalance may act as a potential factor in the pathogenesis of NS.
\end{abstract}

\section{Introduction}

Nephrotic syndrome (NS) is an alteration of renal function due to an increase in the glomerular basement membrane permeability to plasma protein such as albumin. Signs and symptoms include; edemam, marked or persistent proteinuria and hypoalbuminemia. Three types of NS have been identified: primary minimal change NS (MCNS), secondary NS and congenital NS. Minimal change NS (MCNS) is the most common type, it accounts for 80 percent of the cases and occurs at any age, and it's more commonly found in males (Jaffe, 2012).

The pathogenesis is not yet fully understood; it may be a metabolic, biochemical, or immune disorders that cause an increased permeability to proteins (Van Den Berg et 
al., 2004). Several studies have demonstrated elevated serum immunoglobulin $\mathrm{E}$ (IgE) levels in NS patients and hypothesized its active role in the pathophysiology. Meanwhile, it was proposed that abnormal $\mathrm{T}$ cell response and Th2 cytokines are strongly related to the pathogenesis of NS (Grimbert et al., 2003), various evidences indicate that lymphocytes derived from an abnormal immune system alter the permeability of the glomerular capillary wall, suggesting that immune dysfunction plays a role in the pathogenesis of NS, activated macrophages and Th2 lymphocytes may be involved in the pathogenesis of NS, and T-cell dysfunction leads to changes in cytokines, causing a loss of negatively charged glycoproteins within the glomerular capillary wall. Several cytokines are considered prime candidates for the role of mediators of NS. Regulatory $\mathrm{T}$ cells (T-reg) and T-helper17/T-reg ratio has also been suggested as a potential factor in the pathogenesis of this disease, T-reg dysfunction and decrease of their related cytokines, transforming growth factor TGF$\beta$ and interleukin IL-10, have been reported especially, TGF- $\beta$ was suggested as a protective cytokine (Araya et al., 2009). Therefore this study was established to investigate the role of $\mathrm{IgE}$ in the pathogenesis of NS, and to evaluate the clinical characteristics of pediatric steroidresponsive NS patients according to the $\mathrm{IgE}$ and some immune mediators (IL-17A and TGF- $\beta 1)$.

\section{Subjects and Methods}

Fifty three (53) patients with NS were enrolled in the present study, their age range from 2 to 17 years. They were seeking treatment in the nephrology out patient's clinic at Al-Imamain Al-Kadimain Teaching Medical City, Central Child Teaching Hospital and Children Welfare Teaching Hospital in Baghdad from December 2013 to March 2014. Patients were divided into three groups: Group I consisted of 20 patients in relapse while group 2 consisted of 23 patients in remission and group 3 consisted of 10 newly diagnosis or first attack NS. Twenty seven volunteers from children whose takes vaccination, their gender and ages were matched with patients group were considered as a control. All of them received no treatment with no complaint of other chronic or systemic diseases, their age range was (2 to 17) years. All subjects (patients and control) were subjected to measuring protein in urine, serum albumin, and total serum protein and serum cholesterol. Serum samples were separated from the whole blood, aliquated and stored at $-20^{\circ} \mathrm{C}$ until used. The levels of IgE, IL-17A and TGF- $\beta 1$ were determined by using commercially available ELISA kits and performed as recommended in leaflet with kits (IgE/ Bio check / USA; IL-17A/ Bio check / USA; TGF- $\beta 1$ / Ray Bio / USA).

Statistical Analysis: Frequency distribution for selected variables was done first. Among the outcome quantitative variables were described by mean, SE and tested for statistical significance by t-test. The association between 2 categorical variables was assessed by Chisquare test. $\mathrm{P}$ value less than the 0.05 level of significance was considered statistically significant.

The ethical committee of College of Medicine/Al-Nahrain University approved this study, and all samples were obtained with informed consent in accordance with the Al-Imamain Al-Kadimain Teaching Medical City, Central Child Teaching Hospital and Children Welfare Teaching Hospital declaration.

\section{Results and Discussion}

The results revealed that there was no significant difference between patients and 
controls regarding age and gender $(\mathrm{p}>0.05)$. There was male predominance, $(54.7 \%)$ while $(45.3 \%)$ were females, males/females ratio was $1.2: 1$, as shown in table 1 . Furthermore the current study found that 20 $(37.7 \%)$ of patients had allergy while 33 $(62.3 \%)$ of NS were without allergy. Concerning the response to steroid this study showed that high percentage of patients were sensitive to steroid (35. 81\%), while $(8.19 \%)$ were resistant to steroid. On the other hand $25(58 \%)$ patients were with frequent relapse, table 2 .

The current data revealed that there was significant elevation in median serum levels of $\mathrm{IgE}$ and IL-17Ain NS patients as compared with control group (68.28, 89.03 vs. 50.73, 19.72) respectively, ( $\mathrm{P}<0.05 ; \mathrm{P}<$ $0.001)$. Whereas median serum level of TGF- $\beta 1$ was decrease in NS patients (0.33)when compared to controls (0.67), $(\mathrm{P}<0.05)$. On the other hand the present study showed higher ratio of IL-17/TGF- $\beta 1$ in NS patient (132.02) than healthy control (61.71), table (3).

As well as, there were significant differences in median of serum IgE and IL17 concentrations among sub-groups of patients (newly diagnostic patients, patients with relapse and patients with remission states. For $\mathrm{IgE}$ the concentrations were (78.49, $110.43 \& 45.12$ respectively), and for IL-17 the concentrations were (115.03, $97.60 \& 15.74$ respectively). Meanwhile there was no significant differences in TGF$\beta 1$ and IL-17/TGF- $\beta 1$ ratio concentrations among three sub-groups of patients $(0.35$, $0.31 \& 0.91$ respectively) and $(303.15,360.90$ $\& 26.58$ respectively), (table 4$)$.

In addition, the median levels of IgE, IL-17, TGF- $\beta 1$ and IL-17/TGF- $\beta 1$ ratio were higher in positive allergic NS patients than those in negative allergic cases but statistically not significant ( $p>0.05)$, table (5). Regarding the response to steroid this study observed that there are no significant differences in median serum levels of IgE, IL-17 and TGF$\beta 1$ in steroid resistant patients and steroid sensitive patients, as clearly shown in table.

The present study showed that the concentration of IgE in NS patients was higher than healthy control; also, there was a significant higher level of $\operatorname{IgE}$ in relapse phase and in newly diagnosed cases than in cases with remission. This result consistent with several studies which showed that serum IgE level is high in NS at the time of relapse (Araya et al., 2011; Tain et al., 2007).

IgE antibodies may play a role in the development of kidney disease that is related to hypersensitivity reactions. Patients with NS often exhibit increased serum IgE levels and this may be related to sensitivity to steroid treatment (Tan et al., 2011), this fact was consistent with our findings that showed high percentage of patients were sensitive to steroid, but the difference in IgE level that observed between cases of steroid-sensitive NS (SSNS) and steroid-resistant (SRNS) was not significant and this may be due to the low number of cases that resist to steroid. Meanwhile the serum IgE level was significantly higher in SSNS patients in relapse phase compared with SSNS patients in remission phase. A study conducted by Tan Yet al., on MCNS patients is reported that elevated levels of $\operatorname{IgE}$ may be a feature of steroid resistance or relapse, indicating prognostic significance in adult PNS, particularly in MCNS.

Concerning the allergy there was a higher level of $\mathrm{IgE}$ in patients with history of allergy than control group, this finding agreed with other studies which have shown a strong association between NS and atopic disorders. IgE levels were significantly higher in NS patients with atopy than in 
nonatopic patients, especially during the relapse phase of NS compared with the remission phase, implicating $\operatorname{IgE}$ in disease severity with it is prognostic value (Lin et $a l ., 1990)$. In the current work there was no significant difference in IgE level between patients treated with steroid and patient with other treatment, similarly other studies also showed no difference in serum IgE level between cases of SSNS or SRNS. Many patients with MCD have increased serum levels of IgE and IL-13. IL-13 has the ability to cause switch from IgM to IgE in B cells.

Table.1 Demographic Characteristic in Patients Group and Control Group

\begin{tabular}{|l|l|l|l|l|}
\hline \multicolumn{2}{|c|}{} & $\begin{array}{l}\text { Control group N= } \\
27\end{array}$ & Patients groupN=53 & P value \\
\hline \multirow{3}{*}{ Age } & Range & $(2-17)$ & $(2-17)$ & $0.378^{\mathrm{NS}}$ \\
\cline { 2 - 4 } & Mean+SE & $6.72 \pm 0.64$ & $7.43 \pm 0.47$ & \\
\hline \multirow{3}{*}{ Gender } & Female & $12(44.4 \%)$ & $24(45.3 \%)$ & \multirow{2}{*}{$0.567^{\mathrm{NS}}$} \\
\cline { 2 - 4 } & Male & $15(55.6 \%)$ & $29(54.7 \%)$ & \\
\cline { 2 - 4 } & Male /Female & $1.25: 1$ & $1.2: 1$ & \\
\hline
\end{tabular}

$\mathrm{NS}=$ no statistical significant difference $(\mathrm{p}>0.05), \mathrm{SE}=$ Standard Error

Table.2 Clinical Characteristic in Patients Group.

\begin{tabular}{|l|l|l|}
\hline \multicolumn{2}{|c|}{ Allergy } & Patients groupN=53 \\
\cline { 2 - 3 } & Positive & $20(37.7 \%)$ \\
\hline Response to steroid & Sensitive & $33(62.3 \%)$ \\
\cline { 2 - 3 } & Resistant & $35(81 \%)$ \\
\hline Frequency of relapse phase & frequent relapse & $25(58 \%)$ \\
\cline { 2 - 3 } & infrequent relapse & $18(42 \%)$ \\
\hline
\end{tabular}

Table.3 Descriptive Statistics of Serum IgE, IL-17A, TGF- $\beta 1$ and IL-17/TGF- $\beta 1$ Ratio in NS

Patients and Control Group.

\begin{tabular}{|l|l|l|l|}
\hline & \multicolumn{2}{|l|}{ Study groups } & $\begin{array}{l}\text { Mann-Whitney } \\
\text { P-value }\end{array}$ \\
\hline & Controls(N=27) & Patients(N=53) & \multirow{2}{*}{$0.046^{*}$} \\
\hline IgE(IU/ml) & & & \\
\hline Median & 50.73 & 68.28 & $0.001^{* *}$ \\
\hline IL-17(pg/ml) & & & $0.033^{*}$ \\
\hline Median & 19.72 & 89.03 & \\
\hline TGF- $\beta 1(\mathrm{ng} / \mathrm{ml})$ & & & $0.376^{\mathrm{NS}}$ \\
\hline Median & 0.67 & 0.33 & \\
\hline IL-17/TGF- $\beta 1$ & & & 132.02 \\
\hline Median & 61.71 & & \\
\hline
\end{tabular}

*: significant difference; **:highly significant difference 
Table.4 Median of Serum IgE, IL-17, TGF- $\beta 1$ and IL-17/TGF- $\beta$ Ratio in Sub-groups of NS Patients

\begin{tabular}{|l|l|l|l|l|}
\hline \multirow{2}{*}{} & \multicolumn{3}{l|}{ Patients subgroups } & $\begin{array}{l}\text { Kruskal Wallis } \\
\text { p-value }\end{array}$ \\
\cline { 2 - 5 } & Newly(N=10) & Relapse(N=20) & Remission(N=23) & \\
\hline IgE & & & & 0.003 \\
\hline Median & 78.49 & 110.43 & 45.12 & \\
\hline IL-17A & & & & 0.030 \\
\hline Median & 115.03 & 97.60 & 15.74 & \\
\hline TGF- $\beta 1$ & & & & 0.185 \\
\hline Median & 0.35 & 0.31 & 0.91 & \\
\hline IL-17/TGF- $\beta 1$ & & & & 0.229 \\
\hline Median & 303.15 & 360.90 & 26.58 & \\
\hline
\end{tabular}

Table.5 Descriptive Statistics of Serum IgE, IL-17, TGF- $\beta 1$ and IL-17/TGF- $\beta 1$ Ratio in Positive and Negative Allergic NS Cases

\begin{tabular}{|l|l|l|l|}
\hline & Allergy & $\begin{array}{l}\text { Mann-Whitney } \\
\text { P-value }\end{array}$ \\
\hline IgE & Negative(N=33) & Positive(N=20) & \\
\hline Median & & & $0.304^{\text {NS }}$ \\
\hline IL-17A & & 83.40 & \\
\hline Median & 74.63 & & $0.331^{\text {NS }}$ \\
\hline TGF- $\beta 1$ & & 97.21 & \\
\hline Median & 0.42 & & $0.748^{\text {NS }}$ \\
\hline IL-17/TGF- $\beta 1$ & & 0.76 & \\
\hline Median & 127.72 & & $0.486^{\text {NS }}$ \\
\hline
\end{tabular}

Table.6 Descriptive Statistics of Serum IgE, IL-17, TGF $\beta 1$ According the Type of Steroid Response

\begin{tabular}{|l|l|l|l|}
\hline \multicolumn{3}{|l|}{} & \multicolumn{2}{|l|}{ Type of steroid response } & \multirow{2}{*}{ P value } \\
\hline IgE & Sensitive & Resistant & \\
\hline Median & & & \\
\hline IL-17 & 28.97 & 73.16 & $0.067^{\mathrm{NS}}$ \\
\hline Median & & & \\
\hline TGF- $\beta 1$ & 35.16 & 74.63 & $0.657^{\mathrm{NS}}$ \\
\hline Median & & & \\
\hline
\end{tabular}

The Th-17 cell, which secretes factors such as IL-17, IL-22 and IL-23, was implicated in the pathogenesis of inflammatory and autoimmune disease. Shao and other preliminary experiments (in 2009) confirmed that Th-17 and related factors may take part in the leakage of proteinura in PNS, but its mechanism is still unknown (Xiao Shan Shao et al., 2009). The present work showed higher level of IL-17 in 
patients with NS than healthy control. In addition, the current study reveal the higher level of IL-17 in patients with history of allergy than patients without history of allergy, this corresponds with other study which proposed that the concentration of IL17 in the nasal mucosa, nasal secretions and serum levels of allergic rhinitis group were highly compared with control, and on other study suggests a possible role for Th-17associated cytokines in the mechanism of steroid hypo-responsiveness in asthmatic subjects (Tello et al., 2010). The present results have shown higher IL-17 level in resistant steroid patient group than sensitive group. However, the mechanism by which IL-17 induces podocyte apoptosis remains unknown. Th-17/IL-17 may contribute to the pathogenesis of PNS by decreasing the podocalyxin level and inducing podocyteapoptosis. Inflammatory cytokines may induce muscle cell apoptosis via the Fas pathway. IL-17 may induce podocyte apoptosis through a Fas/FasL signaling pathway. However, IL-17 can increase the Fas gene and protein expression levels in podocytes, with increased downstream apoptotic proteins, including Caspase 8 and Caspase 3 eventually leading to increased apoptosis. IL-17-mediated apoptosis will further decrease the number of podocytes and damage the filtration barrier of the glomerulus and cause mass proteinuria. There was a significant lower level of IL-17 in patients on treatment with drug other than steroid as compared with patients on steroid treatment this result agrees with (VazquezTello et al., 2010).

Another important result in this work is the lower level of TGF- $\beta 1$ in NS patients compared with healthy control and according the sub-groups of patients there was a lower level of TGF in relapse and newly diagnosed NS patients than remission phase, this result agree with several studies which found that TGF- $\beta 1$ and IL-10 concentrations decreased in NS patients and positively correlated with circulating T-reg frequencies, which suggested that TGF- $\beta 1$ and IL-10 may play a protective role. Other study showed that prolonged proteinuria gives rise to increased TGF- $\beta 1$ and retarding the progression to renal failure.

According the allergy, the present study reveal a higher level of TGF- $\beta 1$ in patients with history of allergy than patients without history of allergy, this result consistent with other studies which showed that TGF- $\beta 1$ plays a key role in asthma and allergic rhinitis because it mediates leukocyte chemotaxis to pulmonary tissue, a crucial step in maintenance of an inflammatory response.

The present work showed increased of IL$17 / \mathrm{TGF}-\beta 1$ ratio in NS patients compared with healthy control, also this ratio increased in relapse phase and in newly diagnosed NS patients, this result agreed with Liu et al study which revealed that the Th-17/T-reg ratios higher with increased disease activity in patients with NS, and suggesting a potential role of IL-17/TGF- $\beta 1$ imbalance in the pathogenesis of MCNS. According the allergy, the IL-17/TGF- $\beta 1$ ratio increased in patients with history of allergy than negative allergy this result agree with other studies which confirmed that the imbalance between a Th-17/T-reg cell may play a crucial role in allergic airway inflammation and associated with moderate to severe asthma. In addition in this study the IL-17/TGF- $\beta 1$ imbalance was increased in patients treated with steroid compared with patients treated with other medication. Other study showed increase in IL-17/TGF- $\beta 1$ imbalance before treatment and returned to normal after effective corticosteroids therapy. These results indicated that IL-17/TGF- $\beta 1$ imbalance existed in MCNS patients (Liu et al., 2011). In conclusion, patients with NS exhibit increased serum level of $\operatorname{IgE}$ and this may be 
related to sensitivity to steroid treatment. Moreover, IL-17A/TGF- $\beta 1$ ratio imbalance may act as a potential factor in the pathogenesis of NS.

\section{Acknowledgement}

The authors sincerely thank the patients and their families for participating in this work.

\section{References}

Jaffe, M. 2012. Nephrotic syndrome . Pediatric Nursing Care Plans (2nd Ed.). Englewood. ; pp 191.

Van Den Berg, J.G., Weening, J.J., Chand, M.A., et al. 2004. Role Of The Immune System In The Pathogenesis Of Idiopathic Nephrotic Syndrome. Clin. Sci., 107(2): 125-36.

Abdel-Hafez, M., Shimada, M., Lee, P.Y. et al. 2009. Idiopathic Nephrotic Syndrome And Atopy: Is There A Common Link. Am. J. Kidney Dis., 54: 945-953.

Grimbert, P., Audard, V., Remy, P., et al. 2003. Recent approaches to the pathogenesis of minimal-change nephrotic syndrome. Nephrol. Dial. Transplant., 8: 245-248.

Eddy, A.A., Symons, J.M. 2003. Nephrotic syndrome in childhood. The Lancet, $362: 29-639$.

Kanai, T., Shiraishi, H., Yamagata, T., et al. 2010. Th2 cells predominate in idiopathic steroid-sensitive nephrotic syndrome. Clin. Exp. Nephrol., 14: 578-583.

Nakanishi, K., Yoshimoto, T. 2001 .IL-18 is a unique cytokine that stimulates both Th- 1 and Th- 2 responses depending on its cytokine milieu. Cytokine $\alpha$ Growth Factor, 12(1): 53-72.

Araya, C., Diaz, L., Wasserfall, C., et al. 2009. T regulatory cell function in idiopathic minimal lesion nephrotic syndrome. Pediatr. Nephrol., 24: 1691-1698.

Jahan, I., Hanif MandAli, M.A. 2011. Relationship between serum IgE and frequent relapse idiopathic nephrotic syndrome Mymensingh Med. J., 20(3): 484-9.

Tain, Y.L., Chen, T.Y., Yang, K.D. 200. Implication of serum IgE in childhood nephrotic syndrome. Pediatr. Nephrol., 18: 1211-1215.

Cheung, W., Wei, C.L., Seah, C.C., et al. 2004. Atopy serum IgE, and interleukin-13 in steroid responsive nephrotic syndrome. Pediatr Nephrol., 19: 627-632.

Tan, Y., Yang, D., Fan, J. et al. 2011. Elevated levels of immunoglobulin E may indicate steroid resistance or relapse in adult primary nephrotic syndrome, especially in minimal change nephrotic syndrome. J. Int. Med. Res., 39(6): 2307-13.

Salsano, M.E., Graziano, L., Luongo, I. et al. 2007. Atopy in childhood idiopathic nephrotic syndrome. Acta Paediatr., 96: 561-566.

Lin, C.Y., Lee, B.H., Lin, C.C. et al. 1990. A study of the relationship between childhood nephrotic syndrome and allergic diseases. Chest J., 97: 14081411 .

Wang, L., Li, Q., Lijia Wang. et al. 2013. The role of Th17/IL17 in the pathogenesis of primary nephrotic syndrome in children. Kidney blood press Res., 37(4-5): 332-45.

Xiao Shan Shao, Xi Qang Yang, Xiao Dong Zhao et al. 2009. The prevalence of Th17 cells and FOXP3 regulate $\mathrm{T}$ cells (Treg) in children with primary nephrotic syndrome. Pediatr Nephrol., 5: 24(9): 1683-90.

Lu, H.G.., Peng, H., Chen, D.H., et al. 2011. Relationship between allergic symptoms and RORC2 and IL-17 in 
patients with allergic rhinitis. Chinese J. Otorhinolaryngology Head And Neck Surgery, 46(2): 144-8.

Tello, V.A., Semlali, A., Chakir, J. et al. 2010. Induction of glucocorticoid receptor- $\beta$ expression in epithelial cells of asthmatic airways by T-helper type 17 cytokins. Clin. Exp. Allergy, 40(9): 1312-1322.

Kondo, M., Murakawa, Y., Harashima, N. et al. 2009. Roles of proinflammatory cytokines and the Fas/Fas ligand interaction in the pathogenesis of inflammatory myopathies. Immunol., 128: 589-599.

Vazquez-Tello, A., Semlali, A., Chakir, J. et al. 2010. Induction of glucocorticoid receptor-beta expression in epithelial cells of asthmatic airways by T-helper type 17 cytokines. Clin. Exp. Allergy, 40(9): 1312-22.

Kim, J., Shin, J. 2013. Could interleukin-17 be a therapeutic target of steroiddependent minimal change disease? Kidney Int., 84(5): 1049.

Liu, LL., Qin, Y. 2011. Th17/Treg imbalance in adult patients with minimal change nephrotic syndrome. Clin. Immunol., 139(3): 314-20.

Diwakar, R., Pearson, A.L., Colville-Nash, P. et al. 2007. The role played by endocytosis in albumin-induced secretion of TGF-betal by proximal tubular epithelial cells. Am. J. Physiol. Renal Physiol., 292: 1464-1470.

Tran, D.Q. 2012. TGF- $\beta$ : the sword, the wand, and the shield of FOXP3+ regulatory T cells. J. Mol. Cell Biol., 4(1): 29-37.

Shao, X.S., Yang, X.Q., Zhao, X.D. et al. 2009. The prevalence of Th17 cells and FOXP3 regulae $\mathrm{T}$ cells (Treg) in children with primary nephrotic syndrome. Pediatr Nephrol., 24: 1683-1690.

Zhao, J., Lioyd, C.M., Noble, A. 2013. Th17 responses in chronic allergic airway inflammation abrogate regulatory $\mathrm{T}$ cell mediated tolerance and contribute to airway remodeling. Mucosal Immunol., 6(2): 335-346.

Yu-heng, S.H.I., Guo-chao, Wan Huanying, et al. 2011. Coexistence of Th1/Th2 and Th17/Treg imbalances in patients with allergic asthma. Chinese Med. J., 124(13): 1951-1956.

\section{How to cite this article:}

Ahmed Abdul-hassan Abbas, Yasmin Sahib Mahdi and Shatha Hussain Ali. 2013. Immunoglobulin E, Interleukin-17A and Transforming Growth Factor- $\beta 1$ Levels in Children with Nephrotic Syndrome. Int.J.Curr.Microbiol.App.Sci. 5(6): 908-915. doi: http://dx.doi.org/10.20546/ijcmas.2016.506.098 